\title{
Radiation Exposure Reduction of CT Fluoroscopy in Targeting Celiac Plexus for Neurolysis in Chronic Pain Management
}

\author{
AHMED I. EBEED, M.D. \\ The Department of Diagnostic and Interventional Radiology, Faculty of Medicine, Aswan University
}

\begin{abstract}
Background: Conventional CT (Computed Tomography) guided celiac block is the most accurate method for celiac block guidance the lack of real time visualization, radiation exposure \& time consuming call the need for real time CT fluoroscopy guidance which provide adequate real time needle localization and radiation exposure reduction to patient and medical staff.
\end{abstract}

Aim of Study: Describe technical ways that the IR (Intervention Radiology) team can implement ALARA (As Low As Reasonably Achievable) concept focusing on patient, operator and staff, to reduce the amount of radiation used to conduct the procedure.

Patients and Methods: This study was carried out on 30 adult patients suffering from chronic abdominal pain related to infiltrative or metastatic pancreatic cancer or HCC and pain not controlled by WHO analgesic step ladder.

Guided with CT fluoroscopy Celiac plexus neurolysis is performed, maximum filling of the retro-pancreatic space with ethanol is an indication of sufficient neurolysis.

Applying parameters to reduce radiation exposure dose in pre-procedure helical scanning as well as get use of safety parameters of CT fluoroscopy, the total radiation dose exposure was calculated from the patient dose report.

Results: The technique was successfully performed in 30 patients $(100 \%)$.

The mean value of total CT radiation beam intensity used to perform the procedures DLP per celiac plexus was 46.2 mGy X cm.

Conclusion: CT fluoroscopy guided celiac plexus block is an easy and safe method that affords excessive success rates, applying ALARA parameters during the CTF procedure markedly decrease the affected person radiation dose in contrast with use of conventional CT guidance.

Key Words: ALARA concept - Intervention radiology - CT fluoroscopy.

Correspondence to: Dr. Ahmed I. Ebeed, The Department of Diagnostic and Interventional Radiology, Faculty of Medicine, Aswan University

\section{Introduction}

THE celiac plexus is a complicated network of ganglia that relay preganglionic sympathetic and parasympathetic efferent fibers and visceral sensory afferent fibers to the upper abdominal viscera. Located in the retroperitoneal space just inferior to the celiac trunk and along the 2 sides of the aorta, between the levels of T12-L1 disc space and L2 [1]

Conventional fluoroscopy lack accurate anatomical details that is why it is often associated with a higher rate of complications when targeting the celiac plexus, such as vascular and neurologic injury [2] .

The ultrasonography has been described as a simple and cost-effective method for use with celiac plexus blocks, however, the retero peritoneal structures U/S image clarity depend on the patient body habitus and requires a high degree of operator skill and experience [3].

Conventional Computed Tomography (CT) guided celiac block is the most accurate method for celiac block guidance [4], however CT has been limited as an interventional guidance method due to the lack of real time visualization, radiation exposure \& time consuming [5]

The development of new technology contributed to evolution of real time CT fluoroscopy for intervention procedures [6].

Implementing ALARA in Interventional Radiology (IR) is more complex than in a typical radiography room. Minimizing radiation exposure for the patient and the IR personnel, whose dosage is accumulated over many procedures and years, need to optimize the radiation dose. The doses of patient and operator are related, being proportional to the 
scatter from dose of patient. Therefore, by controlling and decreasing the exposure of the patient, the radiation scatter is decreased and the dose of the workers is reduced [7]

Modern multidetector CT scanners include a radiation dose report that delineates the $\mathrm{CT}$ dose index by volume (CTDIvol) and Dose-Length Product (DLP) for each acquired series and gives the DLP for the entire examination, a convenient estimate of the total absorbed dose [8].

CTDIvol value represents a quantification of the emitted radiation but is not an estimate of the patient's radiation dose, the DLP is the product of the CTDIvol and the length of the CT scan and is reported in units of $\mathrm{mGy} X \mathrm{~cm}$, the DLP characterizes the total ionizing energy imparted to the reference phantom for a given examination and can be used to calculate dose to the patient [8] .

Many elements affect the radiation dose during a CT-guided interventional procedure. These factors include the number of scans, slice thickness, pitch, tube current, gantry rotation time, tube voltage, and length of the scan in the longitudinal direction. All of these factors can be modified and should be considered when planning a procedure with the understanding that they will affect the radiation dose [9].

More than $90 \%$ of the patient dose is administered during the helical planning stage of CTguided fluoroscopy. Thus, the greatest dose reduction is achieved by optimizing planning image parameters [10].

Preprocedure helical CT planning images are primarily obtained for lesion localization rather than characterization, allowing the use of very low-dose protocols [8].

Any of the following four steps may be taken to effectively decrease patient dose during the planning phase: (A) Decrease craniocaudal scan length (the $\mathrm{z}$-axis), (B) Decrease beam energy $(\mathrm{kVp}),(\mathrm{C})$ Decrease photon fluence $(\mathrm{mA})$, or $(\mathrm{D})$ Increase pitch [9]

\section{Patients and Methods}

Thirty patients ( 9 females, 21 males), (mean age, $50.4 \pm 4.83$ years), suffering from uncontrolled upper abdominal pain due hepatocellular carcinoma (20 patients) and pancreatic cancer (10 patients) were enrolled in this study between January 2018 to November 2019 in Radiology Department at our University Hospital, referred from outpatient clinic.
The technique done using Toshiba 160-slice AquilionTM PRIME with CT fluoroscopy.

\section{CT fluoroscopy technique:}

1-Pre -procedure planning: The first essential step in real time CT fluoroscopy-guided celiac plexus neurolysis is pre-procedure planning based on previous post contrast diagnostic CT study.

Pre-procedure images were reviewed in details to determine the patient position, CT approach, needle entry site, needle path, and site of neurolytic agent injection.

2- Patient position: The patient was positioned on the CT table to allow for the shortest and least complicated route to the celiac plexus.

3- Helical CT scanning: Scanogram (anteroposterior \& lateral) for proper localization of the dorso-lumbar spine (Dorsal vertebra D12lumbar vertberea L 1) as fixed bony landmark. Initially a low-dose scanning protocol was adjusted to be (30-50mA) for pre-procedure localizing scan encompassing (D12-L1) vertebral bodies (least cranio-caudal scan length based on fixed bony land mark) to determine local anatomy and the optimal skin entry point.

4- CT fluoroscopy: The video monitor was used inside the scanning room. An operator panel was used in the scanning room with controls available for table movement, gantry lift, laser light control and fluoroscopic factors.

Exposures were activated by using a footswitch. The X-ray tube current is adjusted to be $30-50 \mathrm{~mA}$ (depending on the patient body contour) to reduce the patient radiation exposure, compared with conventional CT (150-400mA).

5- Celiac plexus neurolysis: Celiac plexus neurolysis is performed under intravenous conscious sedation, prognostic block performed by injecting a local anesthetic followed by alcohol for celiac plexus block, maximum filling of the retro-pancreatic space with ethanol is an indication of sufficient neurolysis.

The least number of CT guidance scans needed for final placement of the needle were done.

6- Radiation dose sheet: For each procedure, we obtained the average volume CT dose index (CTDIvol) in milligrays and the corresponding cumulative Dose-Length Product (DLP) in milligrays $\mathrm{X}$ centimeters. These values were obtained from the CT scanner at the end of the procedure as a dose summary sheet and were available in the PACS image display. 
The number of CT guidance scans needed for final placement of the needle were recorded.

\section{Statistical methods:}

Statistical analysis was done by IBM personal computer (SPSS Inc., Chicago, Illinois, USA) software package version 25.0. Two types of statistics were done: Descriptive statistics, for example, percentage, mean, SD, and range, and analytic statistics. $p$-value less than 0.05 regarded statistically significant.

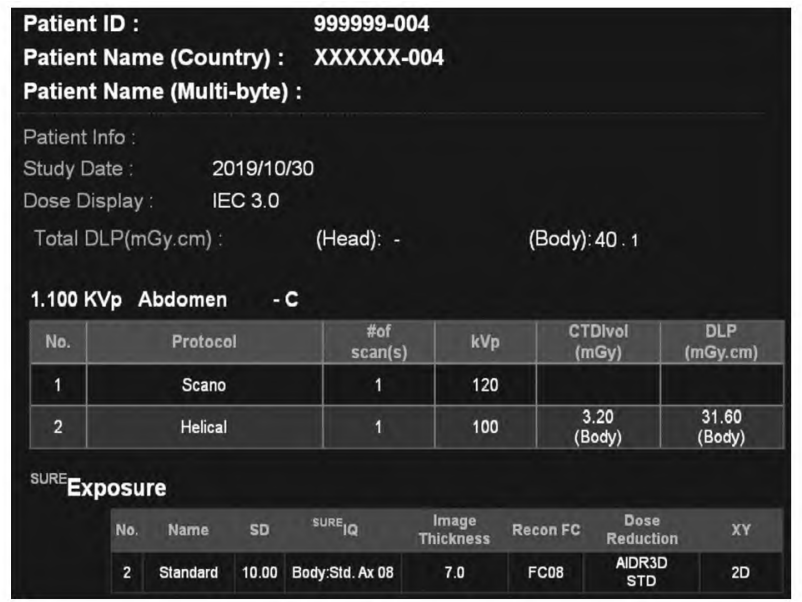

(A)

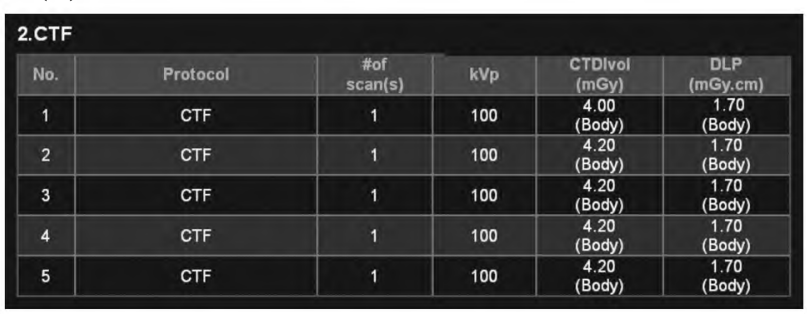

(B)

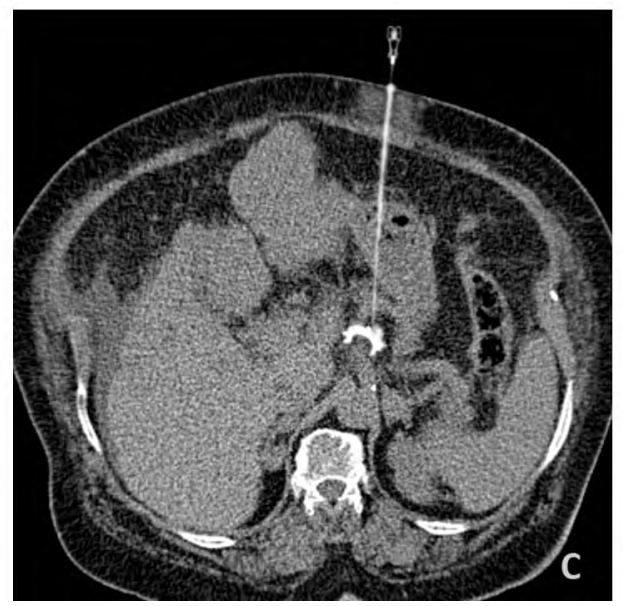

Fig. (1): (A, B) Radiation dose summary sheet, the cumulative dose-length product (DLP) $40.1 \mathrm{mGy} . \mathrm{cm}$, the helical scan DLP was $31.6 \mathrm{mGy} . \mathrm{cm}$, the total number of trials during CTF was 5 times, (C) Final needle position targeting the celiac plexus with adequate contrast perfusion.

\section{Results}

CT-guided CPN was carried out for 30 adult patients. The technique was successfully performed in 30 patients $(100 \%)$, of whom $21(70 \%)$ were males and $9(30 \%)$ were females with mean age $50.4 \pm 4.83$.

For each procedure, we obtained the summary radiation sheet including the cumulative Dose-Length Product (DLP) in milligrays X centimeters, the number of trials till the end of the procedure with maximum filling of the retro-pancreatic space Figs. $(1,2)$.

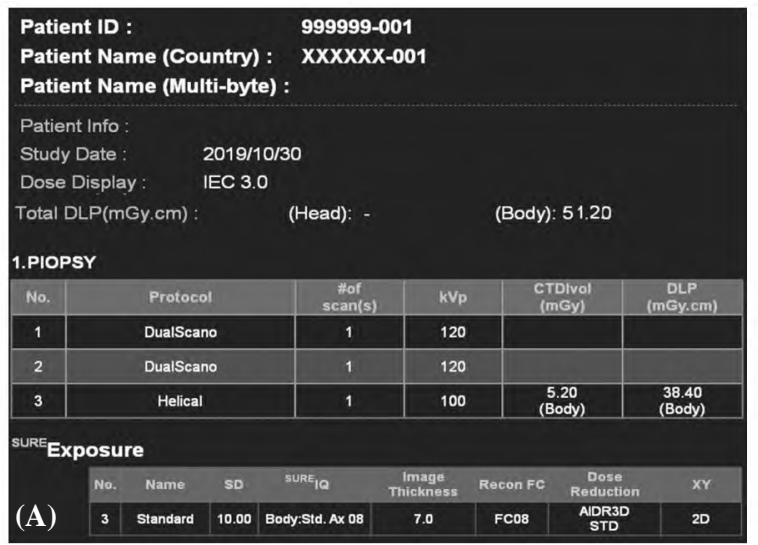

(B)

\begin{tabular}{|c|c|c|c|c|c|}
\hline \multicolumn{6}{|c|}{ 2.CTF } \\
\hline No. & Protocol & $\begin{array}{c}\text { \#fof } \\
\operatorname{scan}(5)\end{array}$ & $k V_{p}$ & $\begin{array}{l}\text { CTDlvol } \\
\text { (mGy) }\end{array}$ & $\begin{array}{c}\text { DLP } \\
(\mathrm{mGy} . \mathrm{cm})\end{array}$ \\
\hline 1 & CTF & 1 & 100 & $\begin{array}{c}4.00 \\
\text { (Body) }\end{array}$ & $\begin{array}{c}1.60 \\
\text { (Body) }\end{array}$ \\
\hline 2 & CTF & 1 & 100 & $\begin{array}{l}4.00 \\
(B o d y)\end{array}$ & $\begin{array}{l}1.60 \\
(B o d y)\end{array}$ \\
\hline 3 & CTF & 1 & 100 & $\begin{array}{l}4.00 \\
(B o d y)\end{array}$ & $\begin{array}{l}1.60 \\
\text { (Body) }\end{array}$ \\
\hline 4 & CTF & 1 & 100 & $\begin{array}{l}4.00 \\
\text { (Body) }\end{array}$ & $\begin{array}{l}1.60 \\
\text { (Body) }\end{array}$ \\
\hline 5 & CTF & 1 & 100 & $\begin{array}{l}4.00 \\
(B \circ d y)\end{array}$ & $\begin{array}{c}1.60 \\
\text { (Body) }\end{array}$ \\
\hline 6 & CTF & 1 & 100 & $\begin{array}{l}4.00 \\
(B o d y)\end{array}$ & $\begin{array}{l}1.60 \\
(B o d y)\end{array}$ \\
\hline 7 & CTF & 1 & 100 & $\begin{array}{c}4.50 \\
\text { (Body) }\end{array}$ & $\begin{array}{c}1.80 \\
(B o d y)\end{array}$ \\
\hline 8 & CTF & 1 & 100 & $\begin{array}{l}4.00 \\
(B o d y)\end{array}$ & $\begin{array}{l}1.60 \\
(B 00 y)\end{array}$ \\
\hline
\end{tabular}

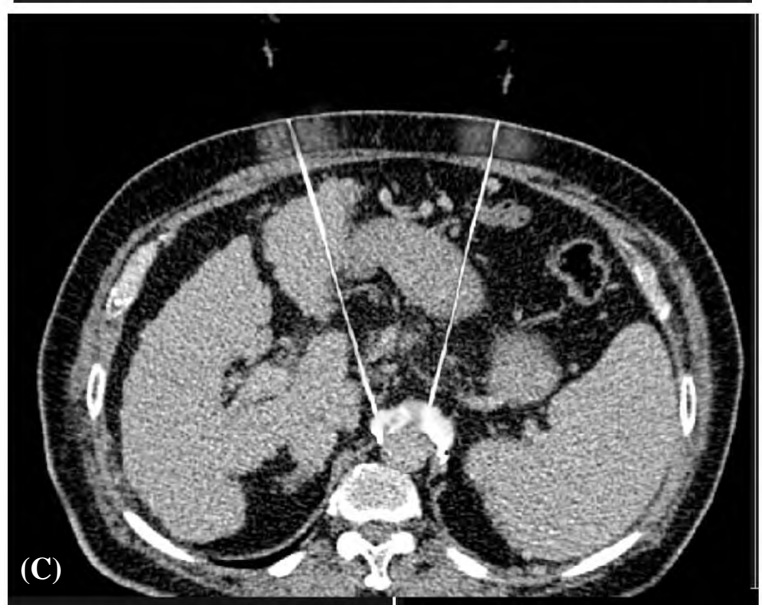

Fig. (2): (A, B) Radiation dose summary sheet, the cumulative Dose-Length Product (DLP) 51.2mGy.cm , the helical scan DLP was $38 \mathrm{mGy} . \mathrm{cm}$, the total number of trials during CTF was 8 times, (C) Bilateral Final needle position targeting the celiac plexus with adequate contrast perfusion. 
The mean number of guiding scans needed to obtain final needle placement is approximately 7 times, the least number of trials was 5 times, the most frequent number was 8 times, only 2 cases of the 30 cases need 9 trials Fig. (3).
The mean radiation dose DLP used to complete the CT fluoroscopy procedure was $46.2 \mathrm{mGy} . \mathrm{cm}$ The mean helical radiation dose DLP was 33.6 mGy.cm (72\% of the total exposure dose), the mean CTF radiation dose DLP was $12.6 \mathrm{mGy} . \mathrm{cm}$ ( $28 \%$ of the total exposure dose) Fig. (4).

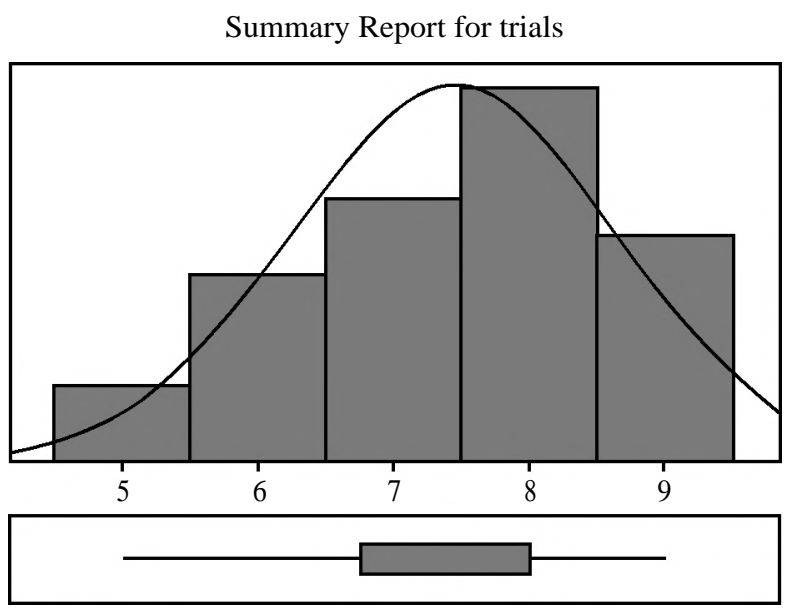

\begin{tabular}{|c|c|}
\hline \multicolumn{2}{|c|}{ Anderson-Darling Normality Test } \\
\hline $\begin{array}{l}\text { A-Squared } \\
p \text {-value }\end{array}$ & $\begin{array}{r}1.10 \\
0.006\end{array}$ \\
\hline Mean & 7.4333 \\
\hline StDev & 1.1943 \\
\hline Variance & 1.4264 \\
\hline Skewness & -0.416763 \\
\hline Kurtosis & -0.655137 \\
\hline $\mathrm{N}$ & 30 \\
\hline Minimum & 5.0000 \\
\hline 1st Quartile & 6.7500 \\
\hline Median & 8.0000 \\
\hline $3^{\text {rd }}$ Quartile & 8.0000 \\
\hline Maximum & 9.0000 \\
\hline \multicolumn{2}{|c|}{ 95\% Confidence Interval for Mean } \\
\hline 6.9874 & 7.8793 \\
\hline \multicolumn{2}{|c|}{$95 \%$ Confidence Interval for Mediar } \\
\hline 7.0000 & 8.0000 \\
\hline \multicolumn{2}{|c|}{ 95\% Confidence Interval for StDev } \\
\hline 0.9512 & 1.6056 \\
\hline
\end{tabular}

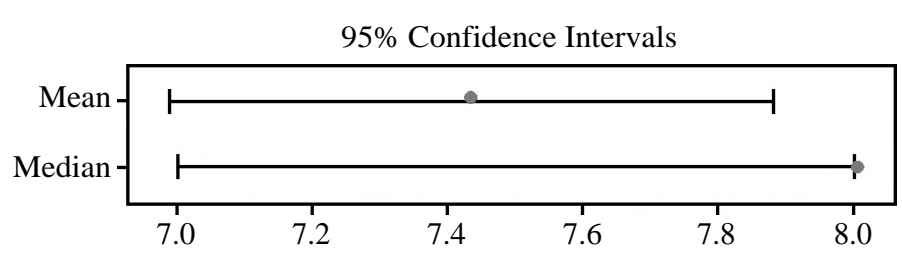

Fig. (3): Graph shows number of guiding scans needed to obtain final needle position.

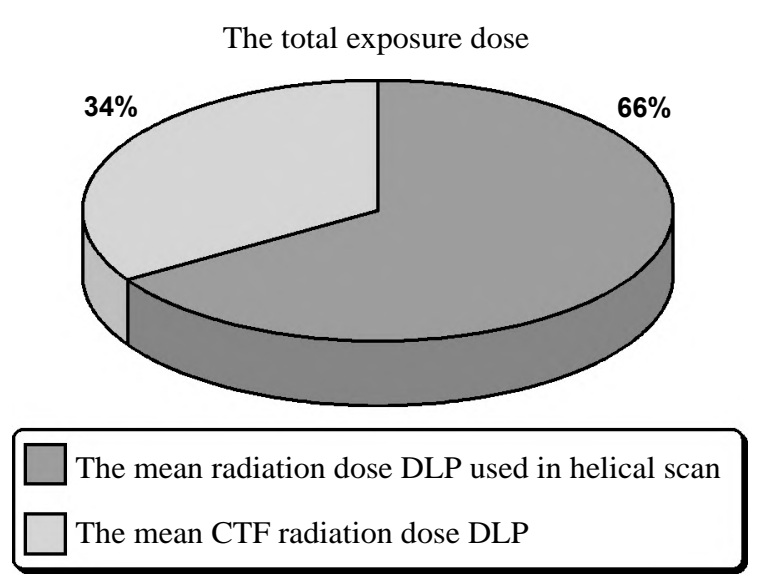

Fig. (4): The mean radiation dose DLP used in helical scan (66\% of the total exposure dose) and the mean CTF radiation dose DLP (34\% of the total exposure dose.

\section{Discussion}

Although the use of CT fluoroscopy carries the hazard of radiation exposure to the patient and operator, the recently used ultra-low dose exposure during the procedure decreased the radiation hazard concern. It provides practitioners with reliable information on the needle position with the real time imaging and the multiplanar reconstruction that makes it less operator dependent, more accurate and less time-consuming tool of guidance than the previously mentioned methods [11] .

To achieve ALARA for patient doses, two independent yet interrelated approaches are required. First the adjustment of the equipment to reduce exit radiation dose during fluoroscopy and radiation dose from documented images during examinations. Second, to minimize the period of radiation exposure. The skilled operator often reduces the number of images captured during the study to the minimum that accurately records the study results and allows correct diagnosis [12]

In our study we meticulously applied parameters to reduced patient radiation exposure dose reducing the radiation dose in helical scan with least craniocaudal scan length based on pre-procedure planning and localizing the target point (celiac plexus) in relation to fixed bony land mark D 12-L 1 as well as reducing the radiation scan dose to the lowest level for proper localization of the celiac plexus. 
We tried to design our studies carefully with adequate pre-procedure planning for the shortest $\&$ safest passage as well as technical training for proper use of CTF help to reduce number of trials for proper needle insertion which help to reduce the cumulative patient radiation dose as we found that the number of trials directly increase CTF dose and total radiation exposure dose.

Occupational radiation protection is necessary, in CT fluoroscopy. To minimize the occupational radiation dose the patient dose should be reduced which proportionally decrease scatter dose to the operator. Therefore, techniques that reduce patient dose will generally also reduce the occupational dose [13]

The use of CT fluoroscopy for the guidance of interventional radiologic procedures markedly decreased patient radiation dose and total procedure time compared with use of conventional CT guidance [10]

Our study confirm that the main radiation exposure dose during CT fluoroscopy was related to the helical planning scanning which represent about two thirds of the whole dose.

We conclude that one of the simplest ways to achieve dose reduction is to reduce the reduce helical scan radiation dose reducing $\mathrm{mAs}$ of the study as well as reducing the scan length as possible.

In our study the patient absorbed dose with CT fluoroscopy was 14.6 time less than absorbed dose with conventional CT as we found that the average DLP of total CTF dose in our study was $46.2 \mathrm{mGy}$ $\mathrm{X} \mathrm{cm}$ at a tube current of $30-50 \mathrm{~mA}$ and tube voltage of $100 \mathrm{kV}$ compared to study done by Joemai et al., [14] which reported an average DLP of 681 $\mathrm{mGy} \mathrm{X} \mathrm{cm}$ for biopsies and drainages while the procedures were completed at a tube current of $100 \mathrm{~mA}$ and tube voltage of $120 \mathrm{kV}$ [14]

Carlson et al., [10] stated that use of CT fluoroscopy to guide interventional radiological procedures significantly reduced patient radiation dose and overall procedural time compared with conventional CT guidance. The median estimated patient absorbed dose per procedure and the median duration of the CT fluoroscopy procedure were 94 per cent lower and 32 per cent lower, respectively, than those measured with traditional CT examination $(p<.05)$.

Celiac plexus is a proper example of a complex anatomical structure need adequate anatomical verification, in this study we did not assess the clinical efficacy of celiac plexus block but addressed the technical results regarding the complex anatomical details beyond the Celiac Plexus Neurolysis (CPN) where the technical success rate was $100 \%$ as regard the proper targeting of the celiac plexus in all patient.

\section{Conclusion:}

During CT-guided interventions, proper pre procedure planning and Technical factors, such as the longitudinal scan length, number of scans, and tube current-time product, can be adjusted to reduce patient radiation dose based on ALARA concept.

CT fluoroscopy guidance for CPN provides high success rates in celiac plexus block as it allows accurate localization of the needle and accurate demonstration of anatomical structures.

\section{References}

1- KAMBADAKONE A., THABET A. and GERVAIS D.: CT-guided Celiac Plexus Neurolysis: A Review of Anatomy, Indications, Technique, and Tips for Successful Treatment. RadioGraphics, 31 (6): pp. 1599-621, 2011.

2- IKI K., FUJITA Y. and INADA H.: Celiac plexus block: Evaluation of injectate spread by three-dimensional computed tomography. Abdom. Imaging, 28 (4): 571-3, 2003.

3- WANG P.J., SHANG M.Y. and QIAN Z.: CT-guided percutaneous neurolytic celiac plexus block technique. Abdom. Imaging, 31 (6): 710-8, 2006.

4- MOORE D.C.: The dreaded complications from neurolytic celiac plexus blocks are preventable! Reg. Anesth. Pain Med., 29 (4): 377-8, 2004.

5- PAULSON E., SHEAFOR D. and ENTERLINE D.: CT Fluoroscopy guided Interventional Procedures: Techniques and Radiation Dose to Radiologists. Radiology, 220 (1): pp. 161-7, 2001.

6- KATADA K., KATO R. and ANNO H.: Guidance with real-time CT fluoroscopy: Early clinical experience. Radiology, 200 (3): pp. 851-6, 1996.

7- BAIRBRE CONNOLLY, JOHN RACADIO, and RICHARD TOWBIN: Practice of ALARA in the pediatric interventional suite, Pediatr. Radiol., 36 (Suppl 2): 1637, Sep., 2006.

8- KEDAR N. CHINTAPALLI 1, RICHARD S. and MONTGOMERY: Radiation Dose Management: Part 1, Minimizing Radiation Dose in CT-Guided Procedures, AJR: 198, April 2012.

9- MARC SARTI, M.D., WILLIAM P. BREHMER, M.D., and SPENCER B. GAY, M.D.: Low-Dose Techniques in CT-guided Interventions; RadioGraphics, 32: 1109-19, 2012 .

10- CARLSON S., BENDER C., CLASSIC K. and ZINK F. Benefits and Safety of CT Fluoroscopy in Interventional Radiologic Procedures. Radiology, 219 (2): pp. 515-20, 2001 
11- WAGNER M., HINSHAW J., and LI Y.: Ultra-Low Radiation Dose CT Fluoroscopy for Percutaneous Interventions: A Porcine Feasibility Study. Radiology, 291 (1): pp. 241-9, 2019.

12- KEITH J. STRAUSS and SUE C. KASTE: The ALARA (as low as reasonably achievable) concept in pediatric interventional and fluoroscopic imaging: Striving to keep radiation doses as low as possible during fluoroscopy of pediatric patients, Pediatr. Radiol., 36 (Suppl 2): 110-2, Sep. 2006
13- DONALD L. MILLER, ELISEO VAÑÓ and GABRIEL BARTAL: Occupational Radiation Protection in Interventional Radiology: A Joint Guideline of the Cardiovascular and Interventional Radiology Society of Europe and the Society of Interventional Radiology, Cardiovasc Intervent Radiol., 33 (2): 230-9, April 2010.

14- JOEMAI R.M., ZWEERS D. and OBERMANN W.R. Assessment of patient and occupational dose in established and new applications of MDCT fluoroscopy, A.J.R., 192: 881-6, 2009.

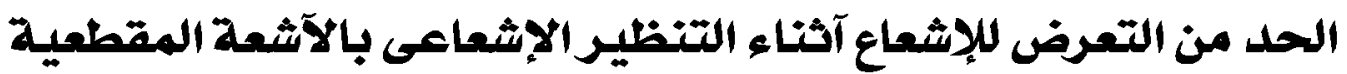

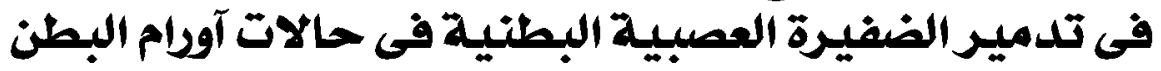

لقد تفقق إستخدام التظظير الإشعاعى بالآشعة المقطعية كمرشد على غيره من الآجهزة من حيث الدقة والآمان حيث يوفر دقة عالية فى إلى

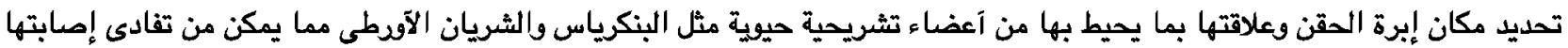
بالإبرة ويساهم فى ثقليل الوقت المطلوب الحقن وتقليل المضاعفات الناتجة عنه.

يهدف هذا البحث إلى إيضاح الوسائل التقنية المتبعه الحد من التعرض للآثـعة آتثاء إستخدام التظظير الإشعاعى بالآشعة المقطعية. هذه الدراسة تم إجراؤها على ثلاثين مريض يعانون من آلام شديدة بالبطن نتيجة لوجود آودام سرطانية بالبطن. خطوات البحث:

• آخد التاريخ المرضى الكامل وتم الإطلاع على الفحوصات السابقة للمريض وصودة دم كاملة مشتملة على عدد الصفائح الدموية وققت وتركيز البريثرمبين.

• مراجعة الآشعة المقطعية على البطن بالصبغة لتصديد الشريان الجوف الباطنى بدقة ومعرفة إذا ما كان هناك آى إختلافات تشريحية عن إنى الوضع الطبيعى وآيضاً تحديد وجود ثانويات وبالتالى وضع خطة دقيقة لتحديد مسار إبرة الحقن وموضع الشبكة العصبية.

• آخذ موافقة كتابية من المريض على إجراء البحث وإخباره بما قد يحدث من مضاعفات ومدة مكثثه فى المستشفى، يتم تحضيره جيداً كما سبق.

• الوسائل التقنية المتبعه للحد من التعرض للآثّعة آثناء إستخدام التنظير الإشعاعى بالآشعة المقطعية هى دقة إختيار المنطقة المستهدفة

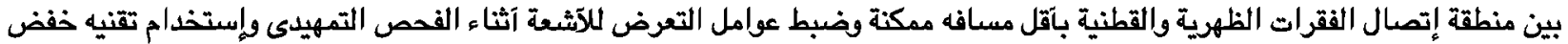
عوامل التعرض للآشعة آثثاء التظظير الإشعاعى حتى الوصول إلى المنطقة المستهدفة.

وبعد التحليل الإحصائى قد خلمست النتائج إلى إنففاض معدل التعرض للآثشعة بمعدل عامره آقل من السبل المتبعه فى الآشعة المقطعية التقليدية مما يقلل من خطورة التعرض الإشعاعى المريض وبالتبعية للآثراد العاملين بالآشعة التداخلية. 